\title{
Efficacy of trabectedin in malignant solitary fibrous tumors: a retrospective analysis from the French Sarcoma Group
}

\author{
J. Khalifa ${ }^{*}$, M. Oualii ${ }^{2+}$, L. Chaltiel ${ }^{2 \dagger}$, S. Le Guellec ${ }^{3}$, A. Le Cesne ${ }^{4}$, J-Y Blay ${ }^{5}$, P. Cousin' ${ }^{5}$ L. Chaigneau ${ }^{6}$, E. Bompas ${ }^{7}$, \\ S. Piperno-Neumann ${ }^{8}$, B. Bui-Nguyen ${ }^{9}$, M. Rios $^{10}$, J-P Delord $^{1}$, N. Penel ${ }^{11}$ and C. Chevreau ${ }^{1}$
}

\begin{abstract}
Background: Advanced malignant solitary fibrous tumors (SFTs) are rare soft-tissue sarcomas with a poor prognosis. Several treatment options have been reported, but with uncertain rates of efficacy. Our aim is to describe the activity of trabectedin in a retrospective, multi-center French series of patients with SFTs.

Methods: Patients were mainly identified through the French RetrospectYon database and were treated between January 2008 and May 2013. Trabectedin was administered at an initial dose of $1.5 \mathrm{mg} / \mathrm{m}^{2}$, q3 weeks. The best tumor response was assessed according to the Response Evaluation Criteria In Solid Tumors 1.1. The Kaplan-Meier method was used to estimate median progression-free survival (PFS) and overall survival (OS). The growth-modulation index (GMI) was defined as the ratio between the time to progression with trabectedin $\left(T T P_{n}\right)$ and the TTP with the immediately prior line of treatment $\left(T T P_{n-1}\right)$.

Results: Eleven patients treated with trabectedin for advanced SFT were identified. Trabectedin had been used as second-line treatment in 8 patients (72.7 \%) and as at least third-line therapy in a further 3 (27.3\%). The best RECIST response was a partial response (PR) in one patient (9.1\%) and stable disease (SD) in eight patients (72.7 \%). Diseasecontrol rate $(\mathrm{DCR}=\mathrm{PR}+\mathrm{SD})$ was $81.8 \%$. After a median follow-up of 29.2 months, the median PFS was 11.6 months ( $95 \% \mathrm{Cl}=2.0 ; 15.2$ months) and the median OS was 22.3 months ( $95 \% \mathrm{Cl}=9.1$ months; not reached). The median GMI was 1.49 (range: $0.11-4.12$ ).
\end{abstract}

Conclusion: Trabectedin is a very promising treatment for advanced SFTs. Further investigations are needed.

Keywords: Sarcoma, Malignant solitary fibrous tumor, Trabectedin, Growth modulation index

\section{Background}

Solitary fibrous tumors (SFTs) are rare soft-tissue sarcomas with an estimated incidence of $<0.1 / 100,000 /$ year [1]. Initially described in pleura, it is now established that SFTs can occur in almost any extra-pleural site. They develop mainly in people aged $50-70$ years, with a gender ratio of 1:1.

Solitary fibrous tumors constitute a heterogeneous group of rare spindle-cell tumors, with an unpredictable course. Morphologically, SFTs are characterized by a combination

\footnotetext{
* Correspondence: jonathan.khalifa@hotmail.fr

${ }^{\dagger}$ Equal contributors

'Department of Medical Oncology, Institut Claudius Regaud/Institut

Universitaire du Cancer de Toulouse - Oncopôle, 1, avenue Irène Joliot-Curie, 31059 Toulouse Cedex 9, France

Full list of author information is available at the end of the article
}

of alternating hypocellular and hypercellular areas, separated by hyalinized collagen, with hemangiopericytomalike vessels. It should be noted that hemangiopericytomas (initially described as a distinct neoplasm of pericytic origin) and SFTs actually constitute a single entity with a morphological continuum [2].

A large majority of cases are benign neoplasms which have an excellent outcome after complete surgical resection [3]. However, a small proportion of cases follow an aggressive course (recurrence after local treatment or metastatic progression). Increased mitotic activity ( $\geq 4$ mitoses per 10 high-power fields), greater cellularity, cellular polymorphism, and the presence of necrosis are associated with malignant behavior [4].

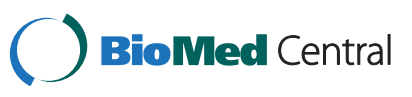

(c) 2015 Khalifa et al. Open Access This article is distributed under the terms of the Creative Commons Attribution 4.0 International License (http://creativecommons.org/licenses/by/4.0/), which permits unrestricted use, distribution, and reproduction in any medium, provided you give appropriate credit to the original author(s) and the source, provide a link to the Creative Commons license, and indicate if changes were made. The Creative Commons Public Domain Dedication waiver (http://creativecommons.org/publicdomain/zero/1.0/) applies to the data made available in this article, unless otherwise stated. 
The standard treatment for localized SFTs is complete surgical resection. No consensus exists on the treatment of advanced stages of this disease. Anthracycline-based chemotherapy or dacarbazine achieve variable response rates, ranging from 0 to $50 \%$ [5-8]. In addition, interesting results have been reported in small retrospective series of patients who had received temozolomide plus bevacizumab [9] or tyrosine kinase inhibitors (sunitinib [10], sorafenib [11], pazopanib [12], and imatinib [13]).

Trabectedin (Yondelis $\left({ }^{\circ}\right)$ [PharmaMar S.A., Madrid, Spain]) is one of the most promising agents to have been developed over the last two decades, and is now an approved treatment for patients with anthracycline/ifosfamide-resistant soft-tissue sarcoma and for those unsuited to these treatments [14, 15]. Objective responses have already been documented in two case reports $[16,17]$.

This retrospective study describes the efficacy and toxicity of trabectedin in advanced SFTs.

\section{Methods \\ Patients}

Most patients were identified through the French RetrospectYon database, which collected data from patients treated with trabectedin between January 2008 and December 2011 in French Sarcoma Group centers. Additional patients were identified through the electronic databases of certain French cancer centers between January 2012 and May 2013.

We collected data on: patients' characteristics at diagnosis; disease characteristics including primary tumor site, extent of disease and pathological features; previous chemotherapy; and clinical outcomes with trabectedin therapy.

This study was approved by the ethics committee of the French Sarcoma Group as well as the scientific board (which permitted access to the RestrospectYon database). Access to local databases was granted by the institutional scientific board of each participating center belonging to the French Sarcoma Group. All patients consented in writing to the anonymized assessment and analysis of clinical data and therapeutic outcome.

\section{Pathology}

Diagnosis was established by pathologists at each French Sarcoma Group center, in accordance with the World Health Organization classification and criteria [18]. Immunologic profile was systematically assessed using CD34 and other antibodies, depending on histopathological profile.

Tumors were scored according to mitotic index, cellularity, cytonuclear polymorphism, and necrosis. The mitotic index was determined using 10 high-power fields $(\times 400)$; necrosis was assessed with a two-area scale ( $<50 \%$ or $>50 \%$ ). Tumor size was also measured.

\section{Treatment}

Following the French consensus, trabectedin was given at the approved initial dose of $1.5 \mathrm{mg} / \mathrm{m}^{2}$ as a $24-\mathrm{h}$ continuous i.v. infusion every three weeks, along with antiemetic prophylaxis and a granulocyte colony-stimulating factor. Dose reductions (from 1.5 to $1.2 \mathrm{mg} / \mathrm{m}^{2}$, and then to $1 \mathrm{mg} / \mathrm{m}^{2}$ ) were decided in cases of toxicity. The standard number of cycles in patients with disease control was six, and maintenance therapy was an option (depending on clinical benefit and the absence of toxicity) at the discretion of the physician.

\section{Response assessment \\ Radiological assessment}

Disease status was retrospectively assessed from a CT scan at baseline and every 2-3 months. Response to treatment was judged by applying the Response Evaluation Criteria in Solid Tumors (RECIST 1.1) [19]. Disease control rate (DCR) was defined as complete response $(C R)+$ partial response $(P R)+$ stable disease (SD). The clinical benefit rate was defined as DCR $\geq$ 6 months [10].

\section{Growth-modulation index (GMI)}

The growth-modulation index (GMI) is a concept introduced in 1998 by Von Hoff [20, 21] to compare successive times to progression (TTP) in an individual patient. It is defined as the ratio between the TTP with an experimental treatment $\left(\mathrm{TTP}_{\mathrm{n}}\right)$ and the TTP with the immediately prior line of treatment $\left(\mathrm{TTP}_{\mathrm{n}-1}\right)$. Because TTPs tend to be shorter with each treatment line, it has been proposed that a GMI $>1$ or even $>1.33$ could be a surrogate for drug activity in phase II trials.

\section{Statistical analyses}

The data are presented using frequency and percentage for categorical variables and median and range for continuous variables.

All survival times were calculated from the date of first administration of trabectedin, and were estimated by the Kaplan-Meier method using the following first-event definitions: progression according to RECIST or death for progression-free survival (PFS) and death from any cause for overall survival (OS). Patients who were still progression-free were censored at the time of their last follow-up. All statistical analyses were conducted using STATA 13.0 software. 


\section{Results}

Patients

We identified eleven patients with progressive malignant SFT who were treated with trabectedin between January 2008 and May 2013. Median age at diagnosis was 55 years (range: $37-62$ years). Patient and tumor characteristics are summarized in Table 1.

\section{Treatment}

All patients had received prior chemotherapy. Trabectedin was used as a second-line treatment in eight patients (72.7 \%): six had previously received anthracycline-based chemotherapy and two a targeted therapy; it was at least third-line treatment in three patients $(27.3 \%)$. The best RECIST response to a prior therapy was a PR in one patient $(9.1 \%)$ and SD in seven (63.6\%).

Table 1 Patient and disease characteristics

\begin{tabular}{|c|c|}
\hline Characteristic & \\
\hline Age (years) (median, range) & $55(37-62)$ \\
\hline \multicolumn{2}{|l|}{ Gender } \\
\hline Male & $2(18.2 \%)$ \\
\hline Female & $9(81.8 \%)$ \\
\hline \multicolumn{2}{|l|}{ ECOG performance status at diagnosis } \\
\hline 0 & $7(63.6 \%)$ \\
\hline 1 & $4(36.4 \%)$ \\
\hline \multicolumn{2}{|l|}{ Primary tumor site } \\
\hline Pleura & $5(45.5 \%)$ \\
\hline Abdomen & $2(18.2 \%)$ \\
\hline Pelvis & $2(18.2 \%)$ \\
\hline Ovary & $1(9.1 \%)$ \\
\hline Upper limb & $1(9.1 \%)$ \\
\hline \multicolumn{2}{|l|}{ Pathological characteristics at diagnosis } \\
\hline Mitotic index (/10 HPF $\left.{ }^{\mathrm{a}}\right)$ (median, range) & $9(3-30)$ \\
\hline \multicolumn{2}{|l|}{ Necrosis } \\
\hline No & $6(54.5 \%)$ \\
\hline Yes & $5(45.5 \%)$ \\
\hline$<50 \%$ & 3 \\
\hline$>50 \%$ & 0 \\
\hline Unknown & 2 \\
\hline Tumor size (mm) (median, range) & $145(45-180)$ \\
\hline \multicolumn{2}{|l|}{ Tumor classification at diagnosis } \\
\hline Benign & $1(9.1 \%)$ \\
\hline Malignant & 10 (90.9\%) \\
\hline \multicolumn{2}{|l|}{ Stage of disease at diagnosis } \\
\hline Local & $9(81.8 \%)$ \\
\hline Metastatic & $2(18.2 \%)$ \\
\hline
\end{tabular}

a/10 high-power fields
All patients were metastatic and had disease progression at the start of trabectedin therapy (local progression: $63.6 \%$; distant progression: $100 \%$ ).

Patients received a median of nine cycles of treatment (range: 2-12). Median treatment duration was 6.1 months (range: 1-11.5 months). All patients received a standard dose of $1.5 \mathrm{mg} / \mathrm{m}^{2}$ except for one who was started on $1.2 \mathrm{mg} / \mathrm{m}^{2}$. Two patients (18.2 \%) required dose reduction because of toxicity.

Reasons for stopping trabectedin were disease stabilization after at least six cycles $(n=5,45.5 \%)$, progressive disease $(n=4,36.3 \%)$, and toxicity $(n=2,18.2 \%)$ (Table 2).

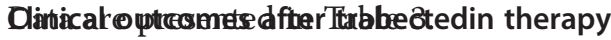

\section{Response}

PR was observed in one patient (9.1\%) and SD in eight patients $(72.7 \%)$. The DCR was $81.8 \%$. Except for one patient, SD and PR were confirmed at 6 months. The clinical benefit rate was thus $72.7 \%$.

Among the eight patients who received trabectedin as a second-line treatment, PR was observed in one patient $(12.5 \%)$ and SD in six patients (75\%), with a DCR of $87.5 \%$.

The median follow-up was 29.2 months (95\% confidence interval $[\mathrm{CI}]=11.7$ months; not reached).

The median PFS was 11.6 months $(95 \% \mathrm{CI}=2.0$; 15.2 months) and the median OS was 22.3 months (95\% CI $=9.1$ months; not reached). The 3- and 6month PFS were respectively $81.8 \%$ (95 \% CI $=44.8$; $95.1 \%)$ and $72.7 \%$ (95\% CI $=37.1 ; 90.3 \%)$. The 12- and 24-month OS rates were respectively $72.7 \%(95 \% \mathrm{CI}=$ 37.1; $90.3 \%$ ) and $37.4 \%$ (95 \% CI = 9.5; $66.3 \%$ ) (Fig. 1). At the time of analysis, five patients were alive (45.6\%) and only one had progressive disease.

\section{GMI}

The median TTP with the last-line treatment before trabectedin (median TTP1) was 5.6 months (range: 1.925.3 months). The median growth modulation index was 1.49 (range: $0.11-4.12$ ). For four patients, the GMI was higher than 2. Data were missing for two patients who had not progressed after trabectedin but whose predictive GMI was also higher than 2. In total, seven patients had a GMI (actual or predictive) of $>1.33$ (63.6 \%, $95 \%$ $\mathrm{CI}=[30.8-89.1 \%])$ (Fig. 2).

\section{Toxicity}

Grade 3-4 toxicity with trabectedin was observed in only three patients $(27.3 \%)$, and was essentially hematologic and hepatic (elevation in hepatic transaminases $>5 \times$ ULN). Two patients $(18.2 \%)$ required a dose reduction and two patients had to stop trabectedin 
Table 2 Previous treatments and trabectedin administration

\begin{tabular}{|c|c|c|c|c|c|c|c|}
\hline $\begin{array}{l}\text { Pt } \\
\text { no. }\end{array}$ & $\begin{array}{l}\text { Prior systemic treat. } \\
\text { before trab. }\end{array}$ & $\begin{array}{l}\text { Best RECIST response to } \\
\text { systemic treatments }\end{array}$ & $\begin{array}{l}\text { Reason for } \\
\text { discontinuing } \\
\text { therapy }\end{array}$ & $\begin{array}{l}\text { Disease status just } \\
\text { before starting trab. }\end{array}$ & $\begin{array}{l}\text { Numb of } \\
\text { trab. cycles }\end{array}$ & $\begin{array}{l}\text { Dose } \\
\text { decr. }\end{array}$ & $\begin{array}{l}\text { Reason for } \\
\text { stopping trab. }\end{array}$ \\
\hline \multirow[t]{4}{*}{$1^{a}$} & $\mathrm{~A} \rightarrow$ & $\mathrm{SD} \rightarrow$ & Stab. & $P D(L+M)$ & 10 & Y & Stab. \\
\hline & Soraf $n^{\circ} 1 \rightarrow$ & $\mathrm{SD} \rightarrow$ & Stab. & & & & \\
\hline & Soraf. $n^{\circ} 2 \rightarrow$ & $\mathrm{SD} \rightarrow$ & Stab. & & & & \\
\hline & Soraf. $n^{\circ} 3 \rightarrow$ & $\mathrm{SD} \rightarrow$ & Progr. & & & & \\
\hline 2 & Soraf & $P D$ & Progr. & $\mathrm{PD}(\mathrm{M})$ & 9 & $\mathrm{~N}$ & Stab. \\
\hline 3 & $\mathrm{Al}$ & PD & Progr. & $P D(L+M)$ & 6 & $\mathrm{~N}$ & Progr. \\
\hline 4 & A & PR & Stab. & $P D(L+M)$ & 12 & Y & Tox. \\
\hline 5 & $\mathrm{Al}$ & SD & Stab. & $\mathrm{PD}(\mathrm{M})$ & 11 & $\mathrm{~N}$ & Stab. \\
\hline \multirow[t]{4}{*}{6} & Ima $\rightarrow$ & $\mathrm{SD} \rightarrow$ & Prog. & $P D(L+M)$ & 12 & $\mathrm{~N}$ & Stab. \\
\hline & $\mathrm{AD} \rightarrow$ & $\mathrm{SD} \rightarrow$ & Stab. & & & & \\
\hline & $\mathrm{Cy} \rightarrow$ & $\mathrm{SD} \rightarrow$ & Progr. & & & & \\
\hline & Soraf. $\rightarrow$ & $\mathrm{PD} \rightarrow$ & Tox. & & & & \\
\hline \multirow[t]{4}{*}{7} & $\mathrm{~A} \rightarrow$ & $\mathrm{SD} \rightarrow$ & Stab. & $P D(L+M)$ & 2 & $\mathrm{~N}$ & Progr. \\
\hline & $\mathrm{Cy} \rightarrow$ & $\mathrm{PD} \rightarrow$ & Progr. & & & & \\
\hline & Suni $\rightarrow$ & $\mathrm{SD} \rightarrow$ & Progr. & & & & \\
\hline & $\mathrm{Bev}+\mathrm{Tmz} \rightarrow$ & $\mathrm{SD} \rightarrow$ & Progr. & & & & \\
\hline 8 & MAID & SD & Stab. & $\mathrm{PD}(\mathrm{M})$ & 4 & $\mathrm{~N}$ & Tox. \\
\hline 9 & $\mathrm{Al}$ & SD & Progr. & $\mathrm{PD}(\mathrm{M})$ & 3 & $\mathrm{~N}$ & Progr. \\
\hline 10 & $A D$ & SD & Stab. & $P D(L+M)$ & 6 & $\mathrm{~N}$ & Stab. \\
\hline 11 & PLK-Inh. & PD & Progr. & $P D(L+M)$ & 11 & $\mathrm{~N}$ & Progr. \\
\hline
\end{tabular}

$L$ local, $M$ metastatic, trab. trabectedin, dose decr. dose decrease, $A$ adriamycin, I ifosfamide, $D$ dacarbazine, $M$ Mesna, Cy cyclophosphamide, Soraf sorafenib, Ima imatinib, Suni sunitinib, Bev $+T m z$ bevacizumab + temozolomide, $P L K$-Inh Polo-Like Kinase inhibitor, SD stable disease, PD progressive disease, $Y$ yes, $N$ no, Stab disease stabilization, Progr disease progression, Tox toxicity

${ }^{\text {aPatient }} 1$ received sorafenib three times, in three successive lines of treatment

Table 3 Clinical outcomes after trabectedin therapy

\begin{tabular}{|c|c|c|c|c|c|c|c|c|}
\hline \multirow[t]{2}{*}{ Pt no. } & \multirow{2}{*}{$\begin{array}{l}\text { Best RECIST } \\
\text { response }\end{array}$} & \multirow{2}{*}{$\begin{array}{l}\text { PFS } \\
\text { (months) }\end{array}$} & \multirow[t]{2}{*}{ Progression } & \multirow{2}{*}{$\begin{array}{l}\text { OS } \\
\text { (months) }\end{array}$} & \multirow{2}{*}{$\begin{array}{l}\text { Status at last } \\
\text { follow-up }\end{array}$} & \multicolumn{3}{|l|}{$\mathrm{GMI}=\mathrm{TTP} 2 / \mathrm{TTP} 1$} \\
\hline & & & & & & TTP1 (months) & TTP2 (months) & GMl \\
\hline 1 & SD & 11.7 & $\mathrm{~N}$ & 11.7 & Alive & 4.9 & - & - \\
\hline 2 & SD & 11.6 & Y & 29.2 & Alive & 5.6 & 11.6 & 2.07 \\
\hline 3 & SD & 3.8 & Y & 9.1 & Dead & 1.9 & 3.8 & 2.02 \\
\hline 4 & SD & 14.6 & Y & 22.3 & Dead & 12.6 & 14.6 & 1.16 \\
\hline 5 & SD & 30.9 & $\mathrm{~N}$ & 30.8 & Alive & 7.1 & - & - \\
\hline 6 & SD & 11.0 & Y & 20.9 & Alive & 3.1 & 11.0 & 3.61 \\
\hline 7 & PD & 1.9 & Y & 7.0 & Dead & 18.7 & 1.9 & 0.11 \\
\hline 8 & $P R$ & 7.5 & Y & 23.4 & Dead & 5.1 & 7.5 & 1.49 \\
\hline 9 & PD & 2.0 & Y & 11.1 & Dead & 7.7 & 2.0 & 0.26 \\
\hline 10 & SD & 15.2 & Y & 17.7 & Dead & 25.3 & 15.2 & 0.6 \\
\hline 11 & SD & 12.3 & Y & 74.2 & Alive & 3.0 & 12.3 & 4.12 \\
\hline Median & & 11.6 & & 22.3 & & 5.6 & 11.6 & 1.49 \\
\hline
\end{tabular}

$S D$ stable disease, $P R$ partial response, $P D$ progressive disease, GMI growth modulation index, $T T P 1$ time to progression with the prior last-line treatment, $T T P 2$ time to progression with trabectedin 

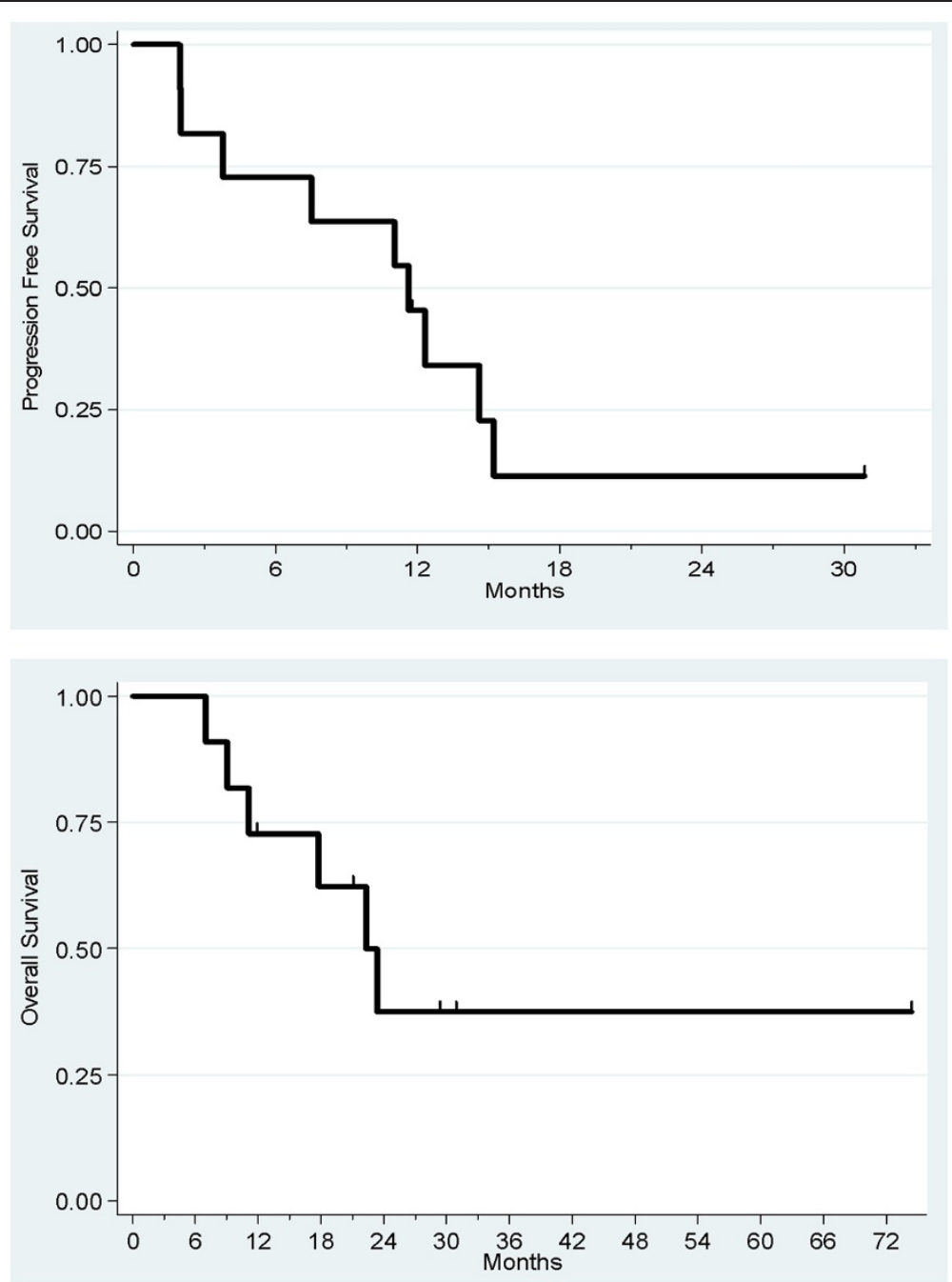

Fig. 1 Kaplan-Meier curves for progression-free and overall survival from the start of trabectedin therapy

because of toxicity, but no toxicity-related deaths were observed.

\section{Discussion}

This study is the first to specifically report on the efficacy of trabectedin in a relatively large sample of patients with an advanced malignant solitary fibrous tumor.

We found very interesting results with an overall response rate of $9.1 \%$ and a DCR of $81.8 \%$. The clinical benefit rate was $72.7 \%$. However, it should be noted that there is no standard definition of the duration of DCR required to qualify as "clinical benefit" in retrospective studies. The median PFS of 11.6 months (95\% $\mathrm{CI}=2.0 ; 15.2$ months) and the median OS of 22.3 months (95\% CI = 9.1 months; not reached) were favorably compared with almost all previous results obtained using conventional chemotherapy or a targeted therapy (Table 4).

The strength of this work was the use of the GrowthModulation Index, a relevant parameter which takes into account the natural course of solitary fibrous tumors. Based on the fact that SFTs are usually slowly progressive diseases, and the fact that TTPs tend to be shorter with successive lines of treatment, a high GMI strongly suggests drug activity.

Cousin et al. showed that GMI was strongly correlated with OS in pre-treated advanced soft-tissue sarcomas [22]. More recently, Penel et al. have shown that a GMI $>1.33$, as reported in our study, was strongly correlated with improved PFS and even OS in advanced soft-tissue sarcoma patients receiving trabectedin as a salvage therapy [23].

Interestingly, we found long-lasting responses with trabectedin, even with non-indolent disease. Indeed, two patients had a long-lasting response in disease that had been rapidly progressive before introducing trabectedin (PFS of 11.0 months and 12.3 months after trabectedin, with a GMI of 3.61 and 4.12, respectively), thus highlighting the impact of trabectedin on the natural 


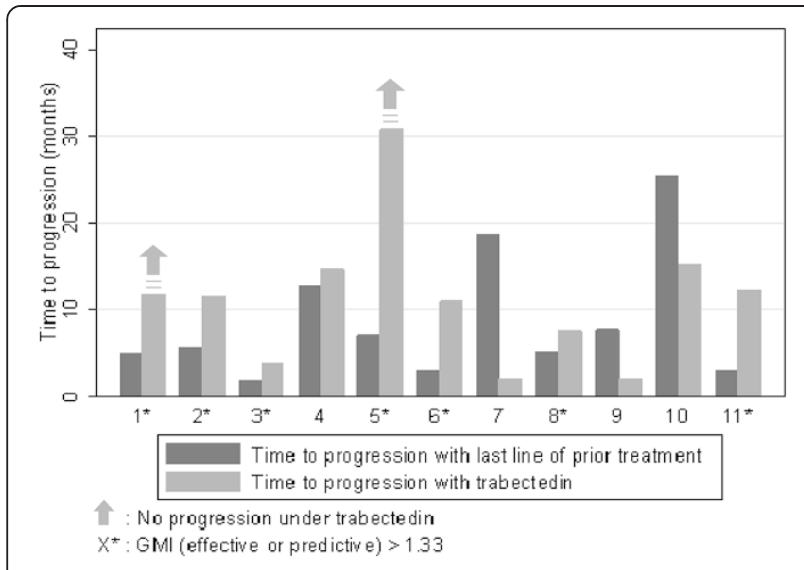

Fig. 2 Comparison of time to progression with trabectedin (TTP2) versus time to progression with prior therapy (TTP1) for the 11 patients. The growth modulation index (GMI) is the ratio between TTP2 and TTP1. Two patients did not progress under trabectedin (patient 1 and patient 5), so that only a minimum predictive GMI could be estimated. All in all, seven patients had a GMI (effective or predictive $)>1.33(63.6 \%, 95 \% \mathrm{Cl}=[30.8-89.1 \%])$

course of this disease. A further patient had nonprogressive disease for 30 months after starting trabectedin therapy (which lasted 9 months) despite presenting with disease progression only 7 months after starting anthracycline-based chemotherapy. In this patient, the predictive GMI was at least 4.28.

Several sources of data suggest the antitumor activity of trabectedin in translocation-related sarcoma. This has been clearly established in the case of myxoid round-cell liposarcoma, where the characteristic chromosomal translocations of $\mathrm{t}(12 ; 16)(\mathrm{q} 13 ; \mathrm{q} 11)$ and $\mathrm{t}(12 ; 22)(\mathrm{q} 13 ; \mathrm{q} 12)$ code for the fusion transcripts FUS-DDIT3 and EWS-
DDIT3, which bind to specific DNA and act as transcription factors for oncoproteins [24]. It has been shown that the antitumor activity of trabectedin in myxoid round-cell liposarcoma was correlated with the expression of the fusion transcript FUS-DDIT3 by interfering with the DNA-binding site of the transcript and by then displacing the transcription factors [25]. Extrapolation of such mechanisms led to the hypothesis that other translocation-related sarcomas (TRS) that express other fusion transcripts may have a particular sensitivity to trabectedin. Thus Le Cesne et al. have provided results from a retrospective pooled analysis of 81 patients with TRS treated with trabectedin in eight phase II trials. They reported an overall control rate of $59 \%$, a median PFS of 4.1 months, and a median OS of 17.4 months [26]. Promising results have also been reported among TRS patients pretreated with conventional chemotherapy in a randomized phase II trial [27].

As regards SFT of the pleura specifically, a recent study assessed the multimodal management of such tumors (all stages included). Twenty-six of the 68 patients had recurrence after first-line treatment. Nine received trabectedin (as a second- or third-line treatment) with a disease control rate of $78 \%$ and a median TTP of 3.4 months [28]. However, responses were not confirmed at 3 months and, above all, no data were available for TTP on the previous line of treatment. Therefore, in contrast to our study, it is not possible to take into account the natural course of the disease.

Lastly, recent data have highlighted NAB2-STAT6 fusion, which is a result of inversion within chromosome 12 , as a distinct molecular feature of SFTs $[29,30]$. In the context of SFTs, NAB2 gains an activation domain

Table 4 Median PFS (by RECIST) and median OS with other treatments for advanced SFT

\begin{tabular}{|c|c|c|c|c|c|c|}
\hline Reference & $\mathrm{n}=$ & Regimen & $\begin{array}{l}\text { Front- } \\
\text { line/ } \\
\text { Further- } \\
\text { line }\end{array}$ & $\begin{array}{l}\text { Median f- } \\
\text { u } \\
\text { (months) }\end{array}$ & $\begin{array}{l}\text { Median PFS } \\
\text { (months) }\end{array}$ & Median OS (months) \\
\hline \multirow[t]{2}{*}{$\begin{array}{l}\text { Stacchiotti } \\
{[6]}\end{array}$} & 31 & Anthracycline-based chemo. & $25 / 6$ & - & 4 (range : 2-15) (front-line : 4) & $\begin{array}{l}11.5 \\
\text { (range : 3-50) }\end{array}$ \\
\hline & 19 & High dose ifosfamide single agent & $11 / 8$ & - & $\begin{array}{l}3 \text { (range : 2-9) (front-line : } 3 \text { (range } \\
: 2-9) \text { ) }\end{array}$ & $\begin{array}{l}11 \\
\text { (range : 3-50) }\end{array}$ \\
\hline Park [5] & $21^{a}$ & $\begin{array}{l}\text { Conventional chemo. (anthracycline- } \\
\text { based/gemcitabine-based/paclitaxel : } \\
\text { 15/5/5) }\end{array}$ & $18 / 7$ & - & $\begin{array}{l}4.6(95 \% \mathrm{Cl}=3.7-5.6) \text { (front-line: } 4.6 \\
(95 \% \mathrm{Cl}=4-5.3))\end{array}$ & $\begin{array}{l}22.8 \\
(95 \% \mathrm{Cl}=3.1-42.6)\end{array}$ \\
\hline $\begin{array}{l}\text { Stacchiotti } \\
{[7]}\end{array}$ & 8 & Dacarbazine & $0 / 8$ & - & 7 (range : 2-12) & - \\
\hline Park [9] & 14 & Bevacizumab + temozolomide & $9 / 5$ & 34 & 10.8 (95 \% Cl = 8.13-not reached) & 24.3 \\
\hline $\begin{array}{l}\text { Stacchiotti } \\
{[10]}\end{array}$ & 35 & Sunitinib & $10 / 25$ & - & $6(95 \% \mathrm{Cl}=4.03-8.01)$ & $\begin{array}{l}16 \\
(95 \% \mathrm{Cl}=12.07-25.9)\end{array}$ \\
\hline $\begin{array}{l}\text { Valentin } \\
{[11]}\end{array}$ & 5 & Sorafenib & $0 / 5$ & - & - & 19.7 \\
\hline
\end{tabular}


from the signaling molecule STAT6, which converts a transcriptional repressor (NAB2) into a potent transcriptional activator (NAB2-STAT6) of EGR1 (Early Growth Response 1), a zinc-finger transcription factor. This leads to the constitutive activation of EGR-mediated transcription target genes such as IGF2, FGF2, PDGFD, or FGFR, which are implicated in the differentiation or proliferation pathways.

By analogy with myxoid liposarcoma, we can hypothesize that trabectedin interferes with the physical interaction of the NAB2-STAT6 fusion protein with EGR1 to ensure its specific anti-tumor activity in SFTs. However, no experimental data exist to suggest this specific effect of trabectedin in SFTs.

Even though an important gap remains between progress in diagnosis and advances in therapy, we are now better able to relate specific sarcoma subtypes to specific treatments [14, 31-34]. Trabectedin could become standard of care in the narrow field of advanced SFTs.

\section{Conclusion}

Our data suggest that trabectedin is a very promising systemic treatment for malignant solitary fibrous tumors and should be strongly considered as an option along with other evidence-based therapies such as anthracyclines, dacarbazine, bevacizumab + temozolomide, sunitinib, and pazopanib.

However, we need further clinical investigations along with the experimental data associated with dedicated phase-II trials to understand the mechanisms of action of trabectedin in this rare sarcoma subtype and to validate this treatment prospectively in larger series of patients.

\section{Abbreviations \\ DCR: Disease-control rate; GMI: Growth-modulation index; OS: Overall survival; PD: Progressive disease; PR: Partial response; RECIST: Response evaluation criteria in solid tumors; SD: Stable disease; TTP: Time to progression.}

\section{Competing interests}

Dr PENEL reports receiving consultation fees from Pharmamar and Bayer HealthCare; research grants from Pharmamar, Novartis, Bayer HealthCare, Roche and Janssen-Cilag; and travel support from Pharmamar and SanofiAventis.

The other authors declare no conflicts of interest.

\section{Authors' contributions}

JK and CC participated in the study's design and coordination. JK, SLG, ALC, $J Y B, P C, L C, E B, S P N, B B N, M R, J P D, N P$, and CC collected the data, participated in the study's design, and interpreted the data. MO and LC performed the statistical analyses, interpreted the data, and helped draft the manuscript. JK analyzed the data and drafted the manuscript. CC revised the final manuscript. All authors have read and approved the final manuscript.

\section{Acknowledgements}

The authors would like to thank Rob Stepney (medical writer, Charlbury, UK), Adnan Tanović, and Newmed Publishing Services for assistance with revising the draft manuscript.

We declare that none of the authors received funding for this study.

\section{Author details}

${ }^{1}$ Department of Medical Oncology, Institut Claudius Regaud/Institut Universitaire du Cancer de Toulouse - Oncopôle, 1, avenue Irène Joliot-Curie, 31059 Toulouse Cedex 9, France. ${ }^{2}$ Department of Statistics, Institut Claudius Regaud / Institut Universitaire du Cancer de Toulouse - Oncopôle, 1, avenue Irène Joliot-Curie, 31059 Toulouse, France. ${ }^{3}$ Department of Pathology, Institut Claudius Regaud / Institut Universitaire du Cancer de Toulouse - Oncopôle, 1, avenue Irène Joliot-Curie, 31059 Toulouse, France. ${ }^{4}$ Department of Medical Oncology, Institut Gustave Roussy, 114 rue Edouard Vaillant, 94805 Villejuif, France. ${ }^{5}$ Department of Medical Oncology, Centre Léon Bérard, 28 Promenade Léa et Napoléon Bullukian, 69008 Lyon, France. ${ }^{6}$ Department of Medical Oncology, Jean Minjoz University Hospital, 3 Boulevard Alexandre Fleming, 25030 Besançon, France. ${ }^{7}$ Department of Medical Oncology, Institut de Cancérologie de l'Ouest, Site Hospitalier Nord Boulevard Jacques Monod, 44805 Saint-Herblain, France. ${ }^{8}$ Department of Medical Oncology, Institut Curie, 26 rue d'Ulm, 75248 Paris, France. ${ }^{9}$ Department of Medical Oncology, Institut Bergonié, 229 cours de l'Argonne, 33000 Bordeaux, France.

${ }^{10}$ Department of Medical Oncology, Centre Alexis Vautrin, 6 Avenue de Bourgogne, 54519 Vandœuvre-lès-Nancy, France. ${ }^{11}$ Department of Medical Oncology, Centre Oscar Lambret, 3 Rue Frédéric Combemale, 59000 Lille, France.

Received: 11 December 2014 Accepted: 7 October 2015

Published online: 15 October 2015

\section{References}

1. Stiller CA, Trama A, Serraino D, Rossi S, Navarro C, Chirlaque MD, et al. Descriptive epidemiology of sarcomas in Europe: report from the RARECARE project. Eur J Cancer. 2013;49:684-95.

2. Gengler C, Guillou L. Solitary fibrous tumour and haemangiopericytoma: evolution of a concept. Histopathology. 2006;48:63-74.

3. Espat NJ, Lewis JJ, Leung D, Woodruff JM, Antonescu CR, Shia J, et al. Conventional hemangiopericytoma: modern analysis of outcome. Cancer. 2002;95:1746-51.

4. England DM, Hochholzer L, McCarthy MJ. Localized benign and malignant fibrous tumors of the pleura. A clinicopathologic review of 223 cases. Am J Surg Pathol. 1989;13:640-58.

5. Park MS, Ravi V, Conley A, Patel SR, Trent JC, Lev DC, et al. The role of chemotherapy in advanced solitary fibrous tumors: a retrospective analysis. Clin Sarcoma Res. 2013;3:7.

6. Stacchiotti S, Libertini M, Negri T, Palassini E, Gronchi A, Fatigoni S, et al. Response to chemotherapy of solitary fibrous tumour: a retrospective study. Eur J Cancer. 2013;49:2376-83.

7. Stacchiotti S, Tortoreto M, Bozzi F, Tamborini E, Morosi C, Messina A, et al. Dacarbazine in solitary fibrous tumor: a case series analysis and preclinical evidence vis-a-vis temozolomide and antiangiogenics. Clin Cancer Res. 2013;19:5192-201.

8. Wong PP, Yagoda A. Chemotherapy of malignant hemangiopericytoma. Cancer. 1978;41:1256-60.

9. Park MS, Patel SR, Ludwig JA, Trent JC, Conrad CA, Lazar AJ, et al. Activity of temozolomide and bevacizumab in the treatment of locally advanced, recurrent, and metastatic hemangiopericytoma and malignant solitary fibrous tumor. Cancer. 2011;117:4939-47.

10. Stacchiotti S, Negri T, Libertini M, Palassini E, Marrari A, De Troia B, et al. Sunitinib malate in solitary fibrous tumor (SFT). Ann Oncol. 2012;23:3171-9.

11. Valentin T, Fournier C, Penel N, Bompas E, Chaigneau L, Isambert N, et al. Sorafenib in patients with progressive malignant solitary fibrous tumors: a subgroup analysis from a phase II study of the French Sarcoma Group (GSF/ GETO). Invest New Drugs. 2013;31:1626-7.

12. Van der Graaf WTA, Blay J-Y, Chawla SP, Kim D-W, Bui-Nguyen B, Casali PG, et al. Pazopanib for metastatic soft-tissue sarcoma (PALETTE): a randomised, double-blind, placebo-controlled phase 3 trial. Lancet. 2012;379:1879-86.

13. De Pas T, Toffalorio F, Colombo P, Trifirò G, Pelosi G, Della VP, et al. Brief report: activity of imatinib in a patient with platelet-derived-growth-factor receptor positive malignant solitary fibrous tumor of the pleura. J Thorac Oncol. 2008:3:938-41.

14. Grosso F, Jones RL, Demetri GD, Judson IR, Blay J-Y, Le Cesne A, et al. Efficacy of trabectedin (ecteinascidin-743) in advanced pretreated myxoid liposarcomas: a retrospective study. Lancet Oncol. 2007;8:595-602.

15. Demetri GD, Chawla SP, von Mehren M, Ritch P, Baker LH, Blay JY, et al. Efficacy and safety of trabectedin in patients with advanced or metastatic 
liposarcoma or leiomyosarcoma after failure of prior anthracyclines and ifosfamide: results of a randomized phase II study of two different schedules. J Clin Oncol. 2009;27:4188-96.

16. Martinez-Trufero J, Alfaro J, Felipo F, Alvarez M, Madani J, Cebollero A. Response to trabectedin treatment in a highly pretreated patient with an advanced meningeal hemangiopericytoma. Anticancer Drugs. 2010;21:795-8.

17. Chaigneau L, Kalbacher E, Thiery-Vuillemin A, Fagnoni-Legat C, Isambert N, Aherfi $L$, et al. Efficacy of trabectedin in metastatic solitary fibrous tumor. Rare Tumors. 2011;3, e29.

18. Guillou L, Fletcher JA, Fletcher CDM, Mandahl N. Extrapleural solitary fibrous tumour and haemangiopericytoma. In: Fletcher CDM, Unni KK, Mertens F editors. World Health Organization classification of tumours. Pathology and genetics of tumours of soft tissue and bone. Lyon: IARC Press 2002; pp. 8690.

19. Eisenhauer EA, Therasse P, Bogaerts J, Schwartz LH, Sargent D, Ford R, et al. New response evaluation criteria in solid tumours: revised RECIST guideline (version 1.1). Eur J Cancer. 2009:45:228-47.

20. Von Hoff DD. There are no bad anticancer agents, only bad clinical trial designs-twenty-first Richard and Hinda Rosenthal Foundation Award Lecture. Clin Cancer Res. 1998:4:1079-86.

21. Von Hoff DD, Stephenson JJ, Rosen P, Loesch DM, Borad MJ, Anthony S, et al. Pilot study using molecular profiling of patients' tumors to find potential targets and select treatments for their refractory cancers. J Clin Oncol. 2010;28:4877-83.

22. Cousin S, Blay JY, Bertucci F, Isambert N, Italiano A, Bompas E, et al. Correlation between overall survival and growth modulation index in pretreated sarcoma patients: a study from the French Sarcoma Group. Ann Oncol. 2013;24:2681-5.

23. Penel N, Demetri GD, Blay JY, Cousin S, Maki RG, Chawla SP, et al. Growth modulation index as metric of clinical benefit assessment among advanced soft tissue sarcoma patients receiving trabectedin as a salvage therapy. Ann Oncol. 2013;24:537-42.

24. Sandberg AA. Updates on the cytogenetics and molecular genetics of bone and soft tissue tumors: liposarcoma. Cancer Genet Cytogenet. 2004;155:1-24.

25. Forni C, Minuzzo M, Virdis E, Tamborini E, Simone M, Tavecchio M, et al. Trabectedin (ET-743) promotes differentiation in myxoid liposarcoma tumors. Mol Cancer Ther. 2009:8:449-57.

26. Le Cesne A, Cresta S, Maki RG, Blay JY, Verweij J, Poveda A, et al. A retrospective analysis of antitumour activity with trabectedin in translocation-related sarcomas. Eur J Cancer. 2012;48:3036-44.

27. Kawai A, Araki N, Sugiura H, Ueda T, Yonemoto T, Takahashi M, et al. Trabectedin monotherapy after standard chemotherapy versus best supportive care in patients with advanced, translocation-related sarcoma: a randomised, open-label, phase 2 study. Lancet Oncol. 2015;16:406-16.

28. Bylicki $\mathrm{O}$, Rouvière $\mathrm{D}$, Cassier $\mathrm{P}$, Chalabreysse L, Levard A, Maury J-M, et al. Assessing the multimodal management of advanced solitary fibrous tumors of the pleura in a routine practice setting. J Thorac Oncol. 2015;10:309-15.

29. Chmielecki J, Crago AM, Rosenberg M, O'Connor R, Walker SR, Ambrogio L, et al. Whole-exome sequencing identifies a recurrent NAB2-STAT6 fusion in solitary fibrous tumors. Nat Genet. 2013;45:131-2.

30. Robinson DR, Wu Y-M, Kalyana-Sundaram S, Cao X, Lonigro RJ, Sung Y-S, et al. Identification of recurrent NAB2-STAT6 gene fusions in solitary fibrous tumor by integrative sequencing. Nat Genet. 2013:45:180-5.

31. Garcia-Carbonero R, Supko JG, Maki RG, Manola J, Ryan DP, Harmon D, et al. Ecteinascidin-743 (ET-743) for chemotherapy-naive patients with advanced soft tissue sarcomas: multicenter phase II and pharmacokinetic study. J Clin Oncol. 2005;23:5484-92.

32. Le Cesne A, Blay JY, Judson I, Van Oosterom A, Verweij J, Radford J, et al. Phase II study of ET-743 in advanced soft tissue sarcomas: a European Organisation for the Research and Treatment of Cancer (EORTC) soft tissue and bone sarcoma group trial. J Clin Oncol. 2005;23:576-84.

33. Yovine A, Riofrio M, Blay JY, Brain E, Alexandre J, Kahatt C, et al. Phase II study of ecteinascidin-743 in advanced pretreated soft tissue sarcoma patients. J Clin Oncol. 2004;22:890-9.

34. Penel N, Bui BN, Bay J-O, Cupissol D, Ray-Coquard I, Piperno-Neumann S, et al. Phase II trial of weekly paclitaxel for unresectable angiosarcoma: the ANGIOTAX Study. J Clin Oncol. 2008;26:5269-74.

\section{Submit your next manuscript to BioMed Central and take full advantage of:}

- Convenient online submission

- Thorough peer review

- No space constraints or color figure charges

- Immediate publication on acceptance

- Inclusion in PubMed, CAS, Scopus and Google Scholar

- Research which is freely available for redistribution

Submit your manuscript at www.biomedcentral.com/submit 